on definitely stated subjects, and who is, as a general rule, expected to complete the duties within a more or less definite time-limit.

For investigations falling under the first category the problem of remuneration presents serious difficulties, and we may at least console ourselves with the knowledge that a step in the right direction has been taken by the Board of Education in requiring returns to be made of researches conducted by the staffs and graduates of our university colleges. In this connection it is, further, becoming recognised that teachers in these institutions should have sufficient opportunity in term time, as well as in vacation, for research.

It is with regard to the second class of investigation that the claim for remuneration is most urgent. From personal knowledge, I consider that it is impossible for an average skilled labourer in the scientific industry to earn a living wage consistent with his necessary expenses unless his whole time is available for remunerative duties. It is true that intervals occur, sometimes quite unexpectedly, during which he may be temporarily unemployed, and these can be utilised for purposes of research; on the other hand, there are certain periods of the year when the work is extremely heavy, and latitude of time is necessary even for the performance of paid work.

There are probably very few scientific labourers who would be justified in refusing an invitation to mark 500 examination papers at a. fee of $I s$. per paper in order to complete an investigation for the Government for which they received no fee. As soon, however, as the labourer accepts remuneration for a definite undertaking, his employer has some guarantee that he will not let future engagements interfere with the fulfilment of his contract. This at least applies to scientific specialists who are not members of trade unions.

I am very much afraid, however, that a great many people are undertaking unpaid work under conditions quite incompatible with the present depressed conditions of the scientific labour market. In some cases this is being done from a sense of patriotism Undoubtedly their labours may have the effect of reducing the duration and the severity of the lesson which the enemy countries are teaching us in regard to our national neglect of science-a lesson which is the one good turn the Huns are doing us. But they are certainly tending to diminish the efficacy of that lesson.

G. H. BRYAN.

\section{Negative Liquid Pressure at High Temperatures.}

IN my paper with Lieut. Entwistle on the effect of temperature on the hissing of water when flowing through a constricted tube (Proc. Royal Soc., A. 9I, I9I5) I have determined the temperature coefficient of an effect which indicates that the tensile strength of water would be zero at a temperature between $279^{\circ} \mathrm{C}$. and $363^{\circ} \mathrm{C}$., with a mean from all the experiments published of $328^{\circ} \mathrm{C}$. Sir Joseph Larmor's calculated result, $265^{\circ} \mathrm{C}$., quoted by him in his letter in Nature of June 29, agrees satisfactorily with the experimental value if we take into account the difficulty of getting the precise point at which hissing ceases, and that the result was obtained by extrapolation from observations taken at temperatures between $12^{\circ} \mathrm{C}$. and $99^{\circ} \mathrm{C}$. Lieut. Entwistle and I have experimented with other liquids-alcohol, benzene, acetone, and ether-and obtained results of a similar character. Experiments are now in abeyance, for my colleague is otherwise engaged.

My own view, formed from physical conceptions, was that the tensile strength of a liquid would become zero at its critical temperature. It is of very great interest that $\mathrm{Sir}$ Joseph has been able to show mathematically that the negative pressure can only subsist at absolute temperatures below $27 / 32$ of the critical point of a substance.

The conclusions appended to our paper are :-

I. That the phenomenon of hissing of water passing a constriction is due to a true rupture of the stream at the point where the pressure is lowest.

2. That the temperatures at which the hissing just occurs, between $0^{\circ}$ and $100^{\circ} \mathrm{C}$., follow a law which may be expressed $\mathrm{V}=\mathrm{C}(\theta-t)$, where $\mathrm{V}$ is the velocity of the stream at a temperature $t, \theta$ the critical temperature of water, and $\mathrm{C}$ a constant.

If we adopt Sir Joseph Larmor's view the latter law will require to be expressed

$$
\mathrm{V}=\mathrm{C} 27 / 3^{2}(\theta+273)-(t+273)
$$

or by a slightly more complex formula.

SIDNEY SKINNER.

South-Western Polytechnic Institute, Chelsea. July 3 .

\section{THE PROPAGATION OF SOUND BY THE ATMOSPHERE.}

SINCE the beginning of the war the sound of gun-firing in Flanders and France has often been heard in the south-eastern counties of England. There can be little doubt as to the origin of the sounds, for the reports of distant heavy guns have a character which is readily recognised. A correspondent of the Daily Mail (July 6) states that at Framfield (near Uckfield), in Sussex, it is easy to identify the particular kind of gun which is being used. The great distance to which the sound-waves are carried under favourable conditions is evident from the letters recently published in the Daily Mail. As firing has occurred lately over a great part of the Western front, the exact position of the source of the sound is uncertain. But if it were in the neighbourhood of Albert the waves must have travelled about i 8 miles to Framfield, ${ }_{50}$ miles to Sidcup, and ${ }^{5} 5^{8}$ miles to Dorking.

Of far greater interest are the form and discontinuity of the sound-area. A remarkable example of the inaudibility of neighbouring reports in the face of a gentle wind was given in the last number of NATure (p. $3^{8}$ ). This is a subject on which many observations have been made since the beginning of the present century, especially in connection with the sounds of volcanic and other explosions. The source of sound is always surrounded by an area of regular or irregular shape within which the sound is everywhere heard, though the source is not always situated symmetrically with reference to the boundary of the area. On several occasions a second sound-area has been mapped, separated from the former by a "silent region" in which no sound is heard. Sometimes this second area partly surrounds the other, sometimes it consists only of isolated patches. As a rule, according to Dr. E. van Everdingen, who has made a detailed study of the subject, ${ }^{1}$ the least distance of the second area from the source is much more

1 "The Propagation of Sound in the Atmosphere." Koninklijke Akad. van Wetenschappente Amsterdam, Proc., vol. xviii., 19r5, pp. $933-960$.

NO. 2437, VOL. 97] 
than $100 \mathrm{~km}$., and the intensity of the sound at this least distance is not less than near the boundary of the inner sound-area.

Dr. van Everdingen refers to several dynamite and volcanic explosions which have been carefully studied from I9O3 to I9II. He also adds some interesting observations made chiefly in Holland during the present war. The most important case is that of the bombardment of Antwerp on October 8, I9I4. The reports were heard at many places in Holland within $100 \mathrm{~km}$. from the source and again outside a circle of ${ }^{5} 5^{8} \mathrm{~km}$. radius, but at very few intermediate places. The silent region is bounded by two curves, which are roughly circular, the inner arc being traced for more than $180^{\circ}$ and the outer for more than $90^{\circ}$. In some cases of heavy firing at later dates there are also indications of silent regions; in others an increased audibility has been established near the line of $160 \mathrm{~km}$. In no case is there any certain indication of any asymmetrical propagation of the sound. ${ }^{2}$

Dr. van Everdingen examines the two explanations which have been offered of the existence of the silent region, one of which relies on variations of wind-velocity and temperature with the altitude; the other (von dem Borne's) on changes in the composition of the atmosphere at great heights. On the former explanation we might expect asymmetry, on the latter symmetry, with regard to the source of sound. He considers that both explanations are true and should be applied in combination. In favour of the second explanation, he urges the facts that in recent cases the outer margin of the silent region has always been about $160 \mathrm{~km}$. from the probable source of sound and that no appreciable deviations from the circular form have been observed. The above distance is greater than the limiting distance (I $44 \mathrm{~km}$.) assigned by von dem Borne, but Dr. van Everdingen shows that it agrees well with estimates made on the supposition that the percentage of hydrogen in the upper atmosphere is much smaller than that assumed by von dem Borne.

There can be no doubt as to the value and interest of Dr. van Everdingen's investigations. It would seem desirable, however, to continue and extend them. Though the existence of silent regions may be regarded as established, many more negative records are required to prove the symmetry of the region with reference to the source of sound. It must be remembered that the deep sounds of these explosions may at great distances be below the lower limit of audibility of some observers. Moreover, the mean radius of the outer margin of the silent region is very far from being constant. In one of the earliest cases in which the silent region was noticed-that of the minute-guns fired during the funeral procession of Queen Victoria on February I, I90I (Knowledge, vol. xxiv., I901, pp. r24-5)-the radius was about $80 \mathrm{~km}$.

C. Davison.

2 It may be mentioned that. on October 28, 1914, the sound of the British naval guns that bombarded the Flemish coast was heard at a distance of $280 \mathrm{~km}$., or 174 miles.

No. 2437 , VOL. 97$]$

\section{AERONAUTICS AND THE WAR.'}

(I) M R. LANCHESTER'S latest book, unlike I his previous works on aerial flight, can be read with considerable interest and without any great effort. The preface, by Lieut.-General Sir David Henderson, at once arrests attention and has caused more comment than any other equally long section of the book. The summary of the present aeronautical position is so interesting that a quotation of considerable length is here given. General Henderson writes :-

There are no experts in military aeronautics; there are experts in the various branches: in flying, in scientitic research, in the design and construction of aeroplanes and engines, in military organisation and tactics. But as yet there is little opportunity for the expert in one branch to gain definite knowledge of the others except by hard personal experience; in every direction there is progress, in every section of work opinion is fluid. . . . Of all the fields in which work for the advancement of military aeronautics has been undertaken in this country, that of scientific research has, up to the present, produced the results that will probably be most enduring. ... In the work of stating and solving the problems of aeronautics, Mr. Lanchester was one of the pioneers; he vas bold enough to publish the results of his investigations at a time when flying had only just been proved possible; and he has reason now to be well satisfied with the quality of his early work.

The author himself, in his introductory note, rubs in the last point very vigorously.

Mr. Lanchester commences by describing the functions of an aeronautical arm, stating that reconnaissance is the main duty, in which aircraft are related to the older arms of the Service. The opposing and destruction of enemy aircraft are classed as secondary functions. The problem of the relative merits of aeroplane and dirigible is treated at some length. Attention is directed to the superior speed of the aeroplane (practically double that of the dirigible). The limit of size is practically reached for the dirigible, whereas the present-day aeroplane nowise defines the limit, in Mr. Lanchester's opinion. This seems scarcely consistent with his present views, for his recent article in Engineering expresses the opinion that large aeroplanes will be less efficient than smaller ones. Mr. Lanchester is doubtful whether fighting is a primary function of the dirigible, and thinks that bomb-dropping is altogether a misuse. He points to the vulnerability of the airship, stating that "even to-day the finest of Germany's fleet of Zeppelins would be absolutely at the mercy of a modern aeroplane in the hands of a man prepared to make his one and last sacrifice." Before proceeding to more general considerations he disposes of the dirigible as a part of the aeronautical service, pointing out that if this proves untrue his main conclusions will not be affected.

The question of the vulnerability of the aero-

1 (r) "Aircraft in Warfare: the Dawn of the Fourth Arm." By F. W Lanchester. Pp, xviii + 222. (London: Constable and Co., Ltd., rgr6.) Price I2s. 6d. net.

(2) "Aircraft in War and Peace." By W. A. Robson. Pp. xi +176. (London: Macmillan and Co., Ltd., 1916.) Price 2s. 6 . net. 